\title{
Lisbeth Salander, una histeria actual
}

\author{
Los hombres que no amaban a las mujeres | Niels Arden Oplev | 2009 \\ La chica que soñaba con una cerilla y un bidón de gasolina | Daniel Alfredson | 2009 \\ La reina en el palacio de las corrientes de aire | Daniel Alfredson | 2009 \\ Jorge Bafico* \\ Facultad de Psicología de la Universidad de la República (UDELAR)
}

Recibido 27 de octubre de 2021; aprobado 4 de noviembre de 2021

\begin{abstract}
Resumen
La trilogía literaria Millennium en la que se basaron los films suecos Los hombres que no amaban a las mujeres, La chica que soñaba con una cerilla y un bidón de gasolina y La reina en el palacio de las corrientes de aire, tienen como protagonista a Lisbeth Salander, personaje que permite trabajar conceptos psicoanalíticos de la histeria, estructura clínica que no sólo funciona como un ordenador que agrupa distintos fenómenos en una misma lógica y permite diferenciarlos de las perversiones y las psicosis, sino que remite a la modalidad por la que se transmite el deseo. Una estructura que acompañó, con la mutación de su sintomatología, los cambios sociales de la historia de la humanidad.
\end{abstract}

Palabras clave: histeria $\mid$ deseo $\mid$ amor $\mid$ síntoma $\mid$ cambio.

Lisbeth Salander, a current hysteria

Abstract

The Millennium literary trilogy on which the Swedish films The Men Who Loved Women, The Girl Who Dreamed of a Match and a Can of Gasoline and The Queen in the Palace of Drafts were based, stars Lisbeth Salander, a character who allows us to work on psychoanalytic concepts of hysteria, a clinical structure that not only works as an structure that groups different phenomena in the same logic and allows them to be differentiated from perversions and psychoses, but also refers to the way desire is transmitted. A structure that accompanied the social changes in the history of humanity with the mutation of its symptoms.

Key words: hysteria | desire | love | symptom | change

Lisbeth Salander, la protagonista de la trilogía $M i-$ llennium ${ }^{1}$ de Stieg Larsson, llevada a la pantalla por la productora sueca Yellow Bird en 2009, a los trece años prendió fuego a su padre. Fue recluida por unos años en un sanatorio psiquiátrico con el diagnóstico de esquizofrenia, y al poco tiempo se le dio de alta bajo la condición de contar con un tutor.

Años después la niña incendiaria se había prostituido en los barrios bajos de Estocolmo.

Lisbeth Salander es bisexual. No quiere amor, sí sexo sin responsabilidad, sin entrega ni pasión. Su cuerpo es extremadamente delgado y está lleno de tatuajes y de piercings.

Tiene muy pocos amigos. Fue víctima de abuso por parte de su tutor, pero la protagonista de Millennium, es capaz de defenderse de él, vengarse y tatuarle en el cuer- po: "Soy un sádico cerdo, un hijo de puta y un violador".

Dejó la prostitución para convertirse en una avezada hacker, trabajando por fuera de la ley. Se venga de los hombres que no aman a las mujeres; lejos de los estereotipos femeninos, lejos, muy lejos de las mujeres reprimidas de la época freudiana, esta muchacha casi esquelética y con los pelos revueltos denuncia y combate un modo de ser del mundo.

Es autosuficiente, activa, vengativa e inteligente y parece ser una de las nuevas figuras feme-ninas que nos ofrece la actualidad. Lisbeth Salander es una inadaptada...

Esta rebelde ha cautivado a más de quince millones de personas en todo el planeta e impuso una moda global entre las mujeres de su generación. Es interesante la cantidad de lecturas diferentes que ha generado la protagonista de Millennium; por ejemplo, el psiquiatra y es-

* jbafico@gmail.com 
critor Ángel García Prieto plantea que Lisbeth: “es una psicópata, con cierto grado de autismo” (Vega, 2021). Vicente Garrido, psicólogo criminalista español, duda que la joven tenga características autistas, y manifiesta que "tiene muchas heridas emocionales por los malos tratos vistos y sufridos, pero no expresa una patología de base genética", y considera que es una mujer "muy endurecida, pero no una sociópata. La vida le ha enseñado a estar muy protegida para no ser herida y ha desarrollado un odio profundo hacia quienes causan el mal. Es capaz de asumir otros roles, por ejemplo, se hace pasar por una chica rica" (Vega, 2021).

Lisbeth Salander refleja múltiples lecturas de sus síntomas...

El escritor Mario Vargas Llosa (2009), escribió:

la novedad, y el gran éxito de Stieg Larsson, es haber invertido los términos acostumbrados y haber hecho del personaje femenino el ser más activo, valeroso, audaz e inteligente de la historia, y de Mikael, el periodista fornicario, un magnífico segundón, algo pasivo pero simpático, de buena entraña y un sentido de la decencia infalible y poco menos que biológico. ¡Bienvenida a la inmortalidad de la ficción, Lisbeth Salander!

Sin embargo, como tantas, Lisbeth Salander es una histérica...

La histeria tiene una larga historia; ya se puede rastrear en 1900 A.C. en un antiguo texto médico egipcio descubierto en Kahoun que la nombra como una enfermedad llamada "perturbaciones del útero". Desde ahí hasta la actualidad, los síntomas que la describen han sido múltiples.

Los tratamientos para la histeria también han variado a través de los siglos, desde la ingesta, en la antigua Grecia, de productos repugnantes, a respirar olores fétidos, a introducir en la vagina perfumes aromáticos, a obligarlas a casarse rápidamente ${ }^{2}$ a sangrías ${ }^{3}$ en Roma; llegando a "tratamientos" tan radicales como los exorcismos y las hogueras en la Edad Media.

La histeria acompañó con la mutación de su sintomatología los cambios sociales de la historia de la humanidad; quizás como ninguna otra estructura. ${ }^{4}$

La clínica de la histeria es siempre el descubrimiento en cada momento, por la plasticidad de sus síntomas que muchas veces escapan a la evaluación y a la clasificación del discurso del amo, cuando éste propone al sujeto los emblemas para identificar y unificar su división.

Los últimos años del siglo XX nos trajeron cambios en lo que a la histeria se refiere: asistimos al nacimiento del DSM, manuales de clasificación de la psiquiatría americana de las enfermedades mentales. Este manual pretende establecer un lenguaje común que sirva a los fines de una comunicación clínica simple, inequívoca y universal. Este intento de simpleza asumió la forma de la supresión del diagnóstico de histeria, sustituyéndolo por innumerables síndromes basados en trastornos que no dejan de pertenecer al territorio de los fenómenos observables.

Es así que la histeria explotó en una serie de trastornos: del estado de ánimo, de ansiedad, somatomorfos, disociativos, sexuales, alimentarios, del sueño, del control de los impulsos, adaptativos, de la personalidad. Todas estas manifestaciones pueden eventualmente encajar perfectamente en la histeria.

La histérica, tema rechazado por la psiquiatría actual, vuelve así bajo la explosión sintomática. Las manifestaciones de la histeria siguen la evolución cultural, social y son fieles a la moda. La histeria, siempre ávida de espectáculos y de publicidad, está particularmente nutrida en esta época. Los medios de comunicación escritos y audiovisuales alimentan sus conocimientos y facilitan su transmisión.

La histérica siempre aparece un paso adelante del clínico, obligando al clasificador a una permanente actualización. Por ejemplo, después del atentado del once de septiembre y de los rumores sobre los envíos terroristas del virus del carbón (anthrax), cientos de mujeres en Estados Unidos, padecieron de manchas rojas en la piel sin causa biológica. Lejos de haber muerto, la histeria está aún más viva.

Las épocas han cambiado, no se trata hoy de represión de la sexualidad, sino de la banalización de la misma. Es una época de caída de los ideales, donde ya no se cree y se promociona el individualismo a ultranza, las histerias se han "adaptado" también a estos tiempos.

La histeria no es solo una categoría clínica sino que funciona como un ordenador que nos permite agrupar muy distintos fenómenos en una misma lógica y diferenciarlos de otras grandes estructuras clínicas como las perversiones y las psicosis. Lacan (2017 [1955-1956]), cuando se plantea el mecanismo de constitución de los síntomas histéricos, coloca en primer lugar a la identificación del síntoma del otro. La importancia para Lacan es acentuar que, aunque el resultado aparente un puro contagio, la vía por la que se produce es la identificación de sujeto a sujeto en el deseo. Esta vertiente clínica le permitió tomar la histeria no solo como una patología sino también como la modalidad misma por la que se transmite el deseo.

Y la transmisión del deseo implica siempre un movimiento que va del sujeto hacia un Otro al que se le dirige una llamada.

Lisbeth, no tiene convulsiones, ni alucinaciones, no 
somatiza, no tiene doble personalidades, no tiene fibromialgias, ni fatigas crónicas, ni trastornos funcionales digestivos, ni dermatológicos, sin embargo, como toda histeria, Lisbeth con su queja y sobre todo, con su dolor, nos dice que hay que hacer algo con el Otro.

Como otras formas de manifestación de la histeria, ofrece como ejes principales: la queja, el dolor y la demanda, pero sobre todo necesita preguntarse qué valor tiene su existencia para el Otro y, hasta dónde el Otro la puede perder.

Mikael Blomkvist, el otro protagonista de Millennium, es un hombre honesto, $\mathrm{y}$ decidido a buscar la verdad de las cosas como sea. Es un personaje bien diferente al de las novelas policíacas: no es alcohólico, no se está muriendo, ni tiene un conflicto existencial.

Como toda histeria que se precie de tal, el hombre es el significante amo, por lo menos para Lisbeth, desde un costado propiciatorio, ya que queda en posición de alentar, sostener y estimularlo. Se convierte, sin explicación aparente, en su compañera inseparable y se ubica como la defensora incondicional de sus ideas y convicciones de justicia; poniendo todo su talento en regocijarse por el prestigio que el otro supuestamente habrá de recibir. Es en este punto donde podrá, entonces, desarrollar la ceguera propia de los atolladeros de su deseo.

Lisbeth Salander y Mikael Blomkvist componen en definitiva una historia de amor. La ilusión de toda histérica: encontrar algún día a un hombre que la ame como se merece. Pues fue desprovista de aquello que ahora le falta, de aquello que espera recibir. "El amor es dar lo que no se tiene" a alguien que no es, señalaba Lacan (2003 [1960-1961] p. 45).

Lisbeth, cómo otras histéricas famosas de la historia psicoanalítica, presenta la disposición en hacer abstracción de cualquier manifestación personal con el único fin de reforzar las de su compañero. Se trata de entrampar al otro, confundiéndose con él y haciendo valer incesantemente al deseo que cree es el suyo. $¿$ Lisbeth Salander no es acaso una Dora moderna?

\section{Referencias}

Alfredson, D. (Director) (2009). Millennium 3. La reina en el palacio de las corrientes de aire. [Película]. Yellow Bird.

Alfredson, D. (Director) (2009). Millennium 2. La chica que soñaba con una cerilla y un bidón de gasolina. [Película]. Yellow Bird.

Lacan, J. (2017). El Seminario de Jacques Lacan. Libro 3. Las psicosis. Paidós. (Seminario dictado en 1955-1956).

Lacan, J. (2003). El Seminario de Jacques Lacan. Libro 8. La transferencia. Paidós. (Seminario dictado en 1960-1961).

Larsson, S. (2008). Los hombres que no amaban a las mujeres. Editorial Destino.

Larsson, S. (2008). La chica que soñaba con una cerilla y un bidón de gasolina. Editorial Destino.

Larsson, S. (2009). La reina en el palacio de las corrientes de aire. Editorial Destino.

López, R. (2010, 1 de enero). Comentario al libro: “El dolor y los lenguajes del cuerpo”. [Artículo de blog]. Recuperado de: https:// psicoanalisisymedicina.blogspot.com/

Oplev, N. A. (Director) (2009). Millennium. Los hombres que no amaban a las mujeres. [Película]. Yellow Bird.

Vargas Llosa, M. (2009, 6 de septiembre). Lisbeth Salander debe vivir. El País. https://elpais.com/diario/2009/09/06/opinion/1252188011_850215.html

Vega, L. A. (2021, 6 de septiembre). Todas las caras de Lisbeth Salander. Faro De Vigo.https://www.farodevigo.es/socie$\mathrm{dad} / 2009 / 06 / 21 /$ caras-lisbeth-salander-17927798.html

\footnotetext{
1 Trilogía Millennium de Stieg Larsson: Los hombres que no amaban a las mujeres (2008), La chica que soñaba con una cerilla y un bidón de gasolina (2008) y La reina en el palacio de las corrientes de aire (2009).

2 Rosa López (2010) plantea en un interesante artículo que esta idea ha sido transmitida a lo largo de la historia y le fue revelada a Freud por uno de sus maestros, el ginecólogo de la Universidad de Viena, Chrobac, quien acunó la célebre frase que aparece en La historia del Movimiento Psicoanalítico: "el tratamiento de la histeria requiere penis normalis en dosis repetutum”. La cuestión del "penis normalis en dosis repetutum" es una creencia que continúa en el imaginario actual.
}

3 El tratamiento se originó en la antigua Roma y consistía en la realización de una pequeña incisión en una vena dejando que la sangre fluyera, o mediante la aplicación de sanguijuelas.

4 Pensemos en la neurosis obsesiva por ejemplo, que sea probablemente la que menos cambios en lo sintomático ha tenido a través del tiempo. 